\title{
TSH stimulates adipogenesis in mouse embryonic stem cells
}

\author{
Min Lu' ${ }^{1}$ and Reigh-Yi Lin ${ }^{1,2,3,4}$ \\ ${ }^{1}$ Department of Medicine, Mount Sinai School of Medicine, Box 1055, One Gustave L Levy Place, New York, New York 10029, USA \\ Departments of ${ }^{2}$ Molecular, Cell and Developmental Biology and ${ }^{3}$ Gene and Cell Medicine, Mount Sinai School of Medicine, New York, New York 10029 , USA \\ ${ }^{4}$ Mount Sinai School of Medicine, The Leon D Black Family Stem Cell Institute, New York, New York 10029, USA \\ (Correspondence should be addressed to R-Y Lin; Email: reigh-yi.lin@mssm.edu)
}

\begin{abstract}
Although TSH is the main regulator of thyroid growth and function, TSH binding activity in fat has long been reported. Since the TSH receptor (TSHR) has been detected in both preadipocytes and adipocytes, we hypothesized that it may play a role in adipose differentiation. Here, we use an in vitro model of adipogenesis from mouse embryonic stem (ES) cells to define TSH function. Directed differentiation of ES cells into the adipose lineage can be achieved over a 3-week period. Although adipocyte differentiation is initiated early in the development of cultured ES cells, TSHR up-regulation is precisely correlated with terminal differentiation of those adipocytes. The adipocytes express TSHR on the cell surface and respond to TSH with increased intracellular cAMP production, suggesting the activation of the protein kinase A
\end{abstract}

signaling pathway. To determine whether TSH impacts adipogenesis, we examined how adipocytes responded to TSH at various points during their differentiation from cultured ES cells. We found that TSH greatly increases adipogenesis when added in the presence of adipogenic factors. More importantly, our data suggest that TSH also stimulates adipogenesis in cultured ES cells even in the absence of adipogenic factors. This finding provides the first evidence of TSH being a pro-adipogenic factor that converts ES cells into adipocytes. It further highlights the potential of ES cells as a model system for use in the study of TSH's role in the regulation of physiologically relevant adipose tissue.

Journal of Endocrinology (2008) 196, 159-169

\section{Introduction}

It is well known that overt hypothyroidism is associated with obesity (Hoogwerf \& Nuttall 1984) and overt hyperthyroidism with weight loss (Baron 1956). Obesity caused by hypothyroidism can be distinguished from that resulting primarily from physical inactivity and a reduced resting metabolic rate by virtue of the accompanying dramatic elevations of thyroid-stimulating hormone (TSH) levels. Sub-clinical hypothyroidism, characterized by elevated TSH levels but normal thyroid hormone levels, is associated with dyslipidemia and an increased risk of ischemic heart disease and mortality (Danese et al. 2000, Hak et al. 2000, Visscher \& Seidell 2001, Imaizumi et al. 2004, Moulin de Moraes et al. 2005). Previous studies have shown that, when adjusted for body mass index, leptin levels are positively correlated with TSH (Iacobellis et al. 2005). Likewise, Iacobellis reported that TSH and body mass index were positively correlated in obese populations with normal thyroid function (Iacobellis et al. 2005). Together, these observations prompt us to speculate that TSH acts directly on the adipose tissue independent of its effect on thyroid function.

TSH binding activity in fat tissue has long been reported (Gorman et al. 1975, Mullin et al. 1976, Davies et al. 1978, Konishi et al. 1982). Since the TSH receptor (TSHR) has been detected in both preadipocytes and adipocytes (Trokoudes et al. 1979, Haraguchi et al. 1996b, 1999, Crisp et al. 1997), we hypothesize that it may play a role in adipose tissue differentiation. Most current strategies rely on primary cultures of adipose tissues or preadipocyte cell lines (Haraguchi et al. 1996a, Bell et al. 2002). Because preadipocytes differentiate from multipotent stem cells of mesodermal origin, this approach precludes the study of anything other than terminal differentiation. In contrast, we have developed a murine embryonic stem (ES) cell-based differentiation model to investigate whether TSH directly regulates differentiation of the earliest stages of adipose development. Murine ES cells are pluripotent stem cell lines isolated from the inner cell mass of 3.5-day blastocysts that can be propagated indefinitely in an undifferentiated state (Evans \& Kaufman 1981, Martin 1981). When ES cells are induced to differentiation in vitro, they form three-dimensional cellular aggregates called embryoid bodies (EBs) that contain derivatives of the three embryonic germ layers and have the potential to differentiate into all cell types of an entire organism (Keller 1995). Using the ES/EB differentiation models, cells with hemangioblast potential have been identified (Choi et al. 1998). ES cellderived hematopoietic precursors (Keller et al. 1993, Keller 1995), neural precursors (Bain et al. 1995, Kawasaki et al. 2000), insulin-producing $\beta$ cells (Lumelsky et al. 2001), and 
cardiomyocytes (Kehat et al. 2004) have been characterized and transplanted into recipient animals. The first observation of adipocyte-like cells derived from ES cells was reported by Field et al. (1992). Importantly, adipogenic gene expression profiles in differentiating ES cells suggest that they encompass the entire spectrum of adipocyte development in vivo (Phillips et al. 2003) and in vitro differentiation of ES cells provides an accessible model system to study adipose progenitor cells that rarely occur in existing primary and immortalized adipocyte cell lines.

Adipocyte differentiation of ES cells can be carried out through a four-stage strategy separated into permissive and terminal differentiation phases (Phillips et al. 2003). Commitment of ES cells to the adipogenic lineage during the permissive phase requires all-trans retinoic acid, the biologically active form of vitamin A (Phillips et al. 2003). Preadipocytes are then induced to differentiate into mature adipocytes during the terminal differentiation phase through treatment with the adipogenic factors insulin, 3,5,3'-triiodo-L-thyronine $\left(\mathrm{T}_{3}\right)$ and the peroxisome proliferation-activated receptor- $\gamma(\operatorname{PPAR} \gamma)$ agonist rosiglitazone (Phillips et al. 2003). This protocol produces significant EB outgrowths with lipid droplet-containing adipose cells.

To determine whether TSH plays a critical role in adipogenesis, we investigated i) whether the expression and function of TSHR in ES cell-derived adipocytes correlates with cellular differentiation and ii) whether TSH can replace adipogenic factors and stimulate adipocyte differentiation. We found that TSHR is expressed in a time- and adipogenicdependent manner in our ES cell differentiation model. In addition, our data suggest that TSH stimulates adipogenesis in cultured ES cells even in the absence of adipogenic factors. This finding provides the first evidence that TSH functions as a pro-adipogenic factor to convert ES cells into adipocytes. It further highlights the potential of cultured ES cells to contribute to the understanding of how $\mathrm{TSH}$ regulates physiologically relevant adipose tissue.

\section{Materials and Methods}

\section{Growth and maintenance of ES cells}

W9.5 ES cells were maintained on irradiated mouse embryonic feeder cells as previously described (Lin et al. 2003, Arufe et al. 2006) in Dulbecco's modified Eagle medium (DMEM, Gibco-BRL) supplemented with 15\% fetal calf serum (FCS), penicillin-streptomycin (100 U/ml, Gibco-BRL), $10 \mathrm{ng} / \mathrm{ml}$ leukemia inhibitory factor (StemCell Technologies Inc., Vancouver, Canada), and $1.5 \times 10^{-4} \mathrm{M}$ monothioglycerol (Sigma). Cultures were maintained in a humidified chamber in a $5 \% \mathrm{CO}_{2}$ /air mixture at $37^{\circ} \mathrm{C}$. ES cell cultures were monitored daily and the cells were passaged at 1:3 ratios every 2 days.

\section{Differentiation of ES cell-derived EBs into adipocytes}

To induce formation of EBs, ES cells were trypsinized into a single-cell suspension and plated at varying densities $\left(10^{3}-8 \times 10^{4}\right.$ cells $\left./ \mathrm{ml}\right)$ in $60 \mathrm{~mm}$ Petri-grade dishes in EB differentiation medium containing Iscove's modified Dulbecco's medium supplemented with penicillin/streptomycin, 15\% fetal bovine serum (FBS), $2 \mathrm{mM}$ L-glutamine, 5\% protein-free hybridoma medium (Gibco-BRL), $0.5 \mathrm{mM}$ ascorbic acid (Sigma), transferrin $(200 \mu \mathrm{g} / \mathrm{ml}$, Boehringer Mannheim), and $1.5 \times 10^{-4} \mathrm{M}$ monothioglycerol for 2 days. Day $2 \mathrm{EBs}$ were then harvested and transferred to new Petri-grade dishes containing DMEM supplemented with 15\% FBS and $1 \mathrm{mM}$ retinoic acid (Fisher Scientific, Pittsburg, PA, USA). Day 5 EBs cultured in the indicated conditions were replated on gelatin-coated six-well plates in DMEM with 15\% KnockOut Serum Replacement Media (SR, Gibco/BRL) supplemented with $0.5 \mathrm{mg} / \mathrm{ml}$ insulin (Sigma), $2 \mathrm{nM} \mathrm{T}_{3}$ (Sigma), and $0.5 \mathrm{mM}$ rosiglitazone (GlaxoSmithKline) for 15 days. In some experiments, TSH induction was carried out with $1 \mathrm{mU} / \mathrm{ml}$ human recombinant TSH (Fitzgerald Industries, Concord, MA, USA).

\section{Gene expression analysis}

Total RNA was isolated with an RNeasy kit (Qiagen) and treated with RNase-free DNase (Qiagen). Two micrograms of total RNA were reverse transcribed into cDNA using Thermoscript First-Strand Synthesis System (Invitrogen). PCR was performed using standard protocols with $2.5 \mathrm{U}$ Platinum Taq polymerase (Invitrogen). Amplification conditions were as follows: initial denaturation at $94{ }^{\circ} \mathrm{C}$ for 2 min followed by $35-40$ cycles of denaturation at $94^{\circ} \mathrm{C}$ for $30 \mathrm{~s}$, annealing at $50-61{ }^{\circ} \mathrm{C}$ for $45 \mathrm{~s}$, extension at $72{ }^{\circ} \mathrm{C}$ for $45 \mathrm{~s}$, and final extension at $72{ }^{\circ} \mathrm{C}$ for $7 \mathrm{~min}$. In all cases, the annealing temperatures were set at $2{ }^{\circ} \mathrm{C}$ below the calculated denaturation temperature. The amount of cDNA in each sample was normalized using $\beta$-actin as a control. RNA controls were included to monitor genomic contamination. The amplified PCR products were separated on $2 \%$ agarose gels and visualized by ethidium bromide staining. The identity of related PCR products was confirmed by direct sequencing. The primers used in this study were as follows:

Adipocyte lipid-binding protein ( $A L B P$; forward) 5'-GATGCCTTTGTGGGAACCTGG-3' ALBP (reverse) 5'-TTCATCGAATTCCACGCCCAG-3' CCAAT/enhancer-binding protein $(C / E B P \alpha$; forward) $5^{\prime}$-CGCAAGAGCCGAGATAAAGC-3' C/EBP $\alpha$ (reverse) 5'-GCGGTCATTGTCACTGGTCA-3' $P P A R \gamma$ (forward) $5^{\prime}$-ATCATCTACACGATGCTGGAA-3' PPAR $\gamma$ (reverse) $5^{\prime}$-CTCCCTGGTCATGAATCCTTG-3' TSHR (forward) $5^{\prime}$-GAGTGTGCGTCTCCACCCTGTGA- $3^{\prime}$ TSHR (reverse) 5'-TTCCAGCCGCTGCAGAGTTGCAT-3' Oct4 (forward) $5^{\prime}$-GGCGTTCTCTTTGGAAAGGTGTTC-3' Oct4 (reverse) 5'-CTCGAACCACATCCTTCTCT-3' $\beta$-actin (forward) 5'-ATGAAGATCCTGACCGAGCG-3' $\beta$-actin (reverse) $5^{\prime}$-TACTTGCGCTCAGGAGGAGC-3' 
Oil red $O$ staining and lipid accumulation assay

Cells were fixed in 4\% paraformaldehyde in PBS for $15 \mathrm{~min}$ at room temperature. The fixed cells were washed with PBS twice at room temperature. Cells were then stained with $0 \cdot 5 \%$ oil red O (Sigma) for $30 \mathrm{~min}$ at room temperature. Next, cells were washed twice with $\mathrm{H}_{2} \mathrm{O}$ for $15 \mathrm{~min}$ to remove the staining solution. Images were captured using a Nikon Eclipse TE2000-S microscope (Morrell Instrument Company Inc., Melville, NY, USA). To evaluate lipid accumulation during differentiation, stained lipids were extracted by $100 \%$ isopropyl alcohol for $5 \mathrm{~min}$, and the optical density of the solution at $540 \mathrm{~nm}$ was measured.

\section{Immunofluorescent microscopy}

Cells were fixed in 4\% paraformaldehyde in PBS. Immunofluorescent staining was carried out using standard protocols as described previously (Lin et al. 2003). In brief, fixed cells were pre-blocked with 3\% BSA in PBS, followed by 1-h incubation with goat anti-mouse TSHR antibody (M-20; 1:500; Santa Cruz Biotechnology Inc., Santa Cruz, CA, USA) at room temperature. For detection of primary antibody, the cells were washed and then incubated with Cy3 affinipure donkey antigoat IgG (1:10 000; Santa Cruz Biotechnology Inc.) for $30 \mathrm{~min}$ at room temperature. The stained cells were washed before mounting with $10 \mu \mathrm{l}$ Vectashield mounting media (Vector Laboratory, Burlingame, CA, USA). Images were captured using a Nikon Eclipse TE2000-S microscope.

\section{Intracellular cAMP measurement}

cAMP responses were measured with the Biotrak cAMP enzyme immunoassay system (Amersham Pharmacia Biotech), as previously described (Lin et al. 2003). Briefly, cells were seeded at $4 \times 10^{4}$ cells/well on flat-bottomed 96-well microtiter plates (tissue-culture grade) 1 day before the assay. The plates were incubated overnight in a $5 \% \mathrm{CO}_{2}$ /air mixture at $37^{\circ} \mathrm{C}$. Cells were stimulated with TSH for $1 \mathrm{~h}$ at $37^{\circ} \mathrm{C}$. Next, $20 \mu \mathrm{l}$ lysis buffer ( $2.5 \%$ dodecyltrimethylammonium bromide) was added to each well. Following the addition of lysis buffer, cells were incubated at room temperature for $10 \mathrm{~min}$ and agitated by vigorous, successive pipetting to facilitate cell lysis. Aliquots $(100 \mu \mathrm{l})$ of lysed cells were transferred to the donkey anti-rabbit Ig coated plate for cAMP assay. Intracellular cAMP was measured with the Biotrak cAMP enzyme immunoassay system according to manufacturers' protocol (Amersham Pharmacia Biotech). A dose-dependent working standard curve (ranging from 12.5 to $3200 \mathrm{fmol}$ ) was generated according to manufacturers' instruction.

\section{Statistical analysis}

Numerical data are expressed as mean \pm s.E.M. An unpaired, two-tailed $t$-test was used for comparison. $P<0.05$ were considered significant.

\section{Results}

TSHR gene expression and function correlate with adipocyte differentiation in cultured ES cells

Although ES cells have been shown to differentiate spontaneously into adipocytes in culture, this occurs relatively rarely. It was necessary to optimize the culture conditions to enhance adipocyte differentiation before ES cells could serve as a useful experimental model. We used a four-stage, twophase differentiation protocol to direct the differentiation of murine ES cells into adipocytes. We began with the expansion of undifferentiated ES cells in the presence of leukemia inhibitory factor (stage 1). When leukemia inhibitory factor is withdrawn, ES cells spontaneously differentiate into three-dimensional cellular aggregates or EBs in suspension (stage 2). Between 2 and 5 days later, the EBs are treated with all-trans retinoic acid. This stage (stage 3), known as the permissive phase, is a prerequisite for commitment of ES cells to the adipose lineage. The final stage (stage 4), known as the terminal differentiation phase, begins when the cells are exposed to the classic adipogenic factors: insulin, $\mathrm{T}_{3}$, and rosiglitazone. This method allows the efficient production of mature adipocyte colonies from the center of EB outgrowths, which are easily identified by oil red $\mathrm{O}$, a specific stain for triglycerides. Figure 1A shows photomicrographs depicting the four stages and two phases of adipocyte differentiation from ES cells.

In order to assess the function of TSH in adipogenesis, we first used semi-quantitative RT-PCR to examine the expression patterns of both TSHR and adipose lineageassociated genes at each stage of the differentiation process. We found that stage 1 ES cells and stage 2 EBs expressed the undifferentiated stem cell marker Oct4 but not TSHR or any of the adipogenic genes (Fig. 1B). After 5 days of differentiation, stage 3 EBs expressed $C / E B P \alpha, P P A R \gamma$, and TSHR. C/EBP $\alpha$, a member of the C/EBP family, is a pleiotropic transcription factor for adipocyte-specific genes. $P P A R \gamma$, the main regulator of adipogenesis, is induced during differentiation and is responsible for activating a number of genes involved in fatty acid binding and storage. Because $C / E B P \alpha$ and $P P A R \gamma$ act synergistically to activate the transcription of genes that produce the adipocyte phenotype, these findings suggest that subpopulations of stage $3 \mathrm{EBs}$ consist of adipocyte progenitor cells committed to the adipose lineage. Further analysis of cells from stage $4 \mathrm{EBs}$ revealed that $C / E B P \alpha P P A R \gamma$, and TSHR gene expression is up-regulated during terminal differentiation (Fig. 1B). Stage 4 EBs also express $A L B P$ (also named adipocyte fatty acid-binding protein, or a-FABP; Matarese \& Bernlohr 1988, Baxa et al. 1989), a marker of terminal differentiation in adipogenesis (Fig. 1B). Our data indicate that adipocyte differentiation and the expression of TSHR are initiated as early as stage 3 in the development of cultured ES cells and that up-regulation of the TSHR gene correlates with the terminal differentiation of adipocytes. 
A
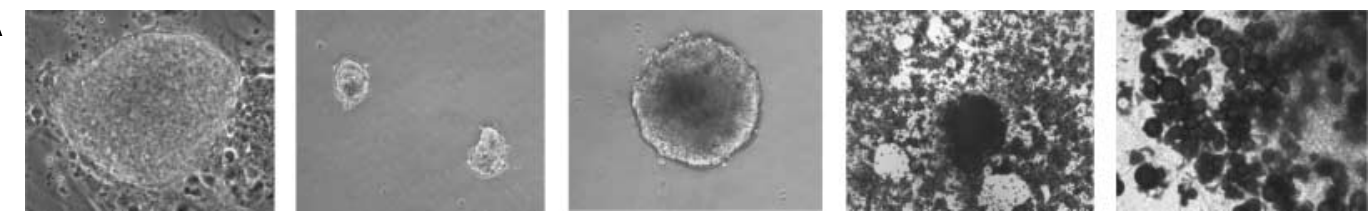

Stage 1:

Stage 2:

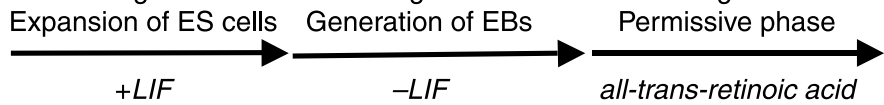

Stage 3:

Stage 4:

Terminal differentiation phase

Adipogenic factors

(Ins/ $T_{3} /$ rosiglitazone)

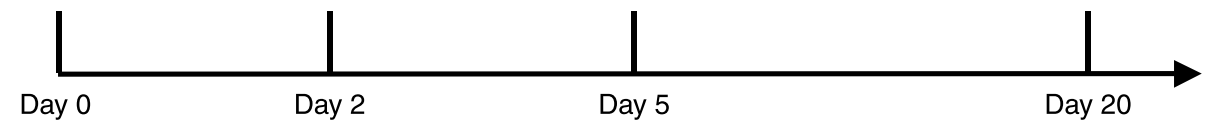

B
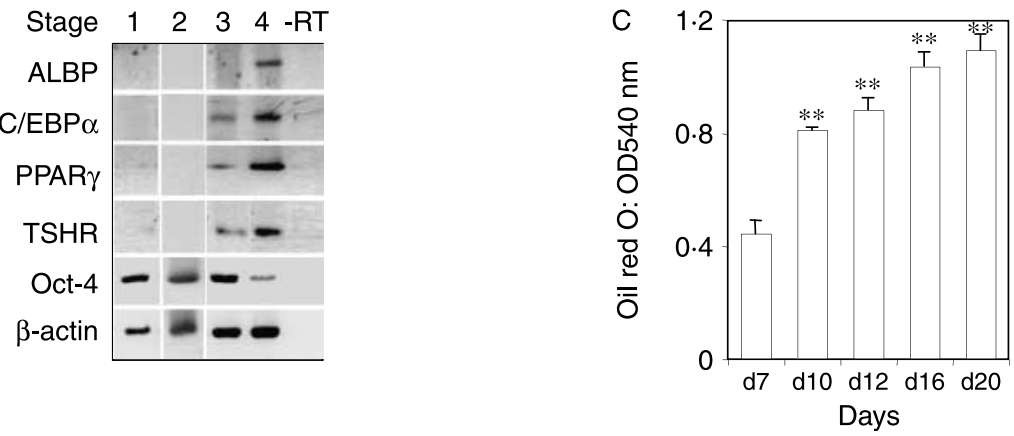

Figure 1 In vitro differentiation of murine ES cells into the adipocyte lineage. (A) Schematic representation of the strategy for differentiation of murine ES cells into adipocytes. Photomicrographs depicting the four stages of ES cell differentiation: undifferentiated ES cells (stage 1), EBs in suspension (stage 2), EBs in the permissive phase (stage 3), and terminally differentiated adipocytes (stage 4). Note stage 4 adipocytes containing lipid droplets developed on an EB outgrowth, visualized by oil red O staining, and shown at two different magnifications (left, $40 \times$, right, $200 \times$ ). (B) Gene expression analysis by RT-PCR shows the differentiation of adipocytes from ES cells. RNA was isolated from undifferentiated ES cells (stage 1), and from the cells grown for 2 days (stage 2), 5 days (stage 3), and 20 days (stage 4), and analyzed for expression of TSHR and the adipocyte marker genes ALBP, C/EBP $\alpha$, and PPAR $\gamma$. Oct4 is an undifferentiated ES cell marker. $\beta$-Actin serves as an internal control. Control experiments contained no reverse transcriptase (-RT). (C) Time course of lipid accumulation. Oil red O-stained lipids were extracted with $100 \%$ isopropyl alcohol from individual cultures, and the absorbance at $540 \mathrm{~nm}$ was measured. Data are expressed as mean \pm s.E.M. Values are from three separate experiments each done in duplicate. ${ }^{* *} P<0 \cdot 005$ compared with $\mathrm{d} 7$.

To investigate the time course of lipid accumulation, we performed oil red $\mathrm{O}$ staining followed by extraction of stained lipids with isopropyl alcohol. The optical density $(540 \mathrm{~nm})$ of the solution was measured after $7,10,12,16$, and 20 days of differentiation (Fig. 1C). Oil red $\mathrm{O}$ as indicator of triglyceride accumulation increased significantly over the 20-day period, reaching $0.81 \pm 0.01$ (arbitrary unit) at day $10(P<0 \cdot 005)$, $0.89 \pm 0.03$ at day $12(P<0.005), 1.04 \pm 0.05$ at day 16 $(P<0 \cdot 005)$, and $1 \cdot 10 \pm 0 \cdot 06$ at day $20(P<0 \cdot 005)$. Consistent with adipose gene expression profile (Fig. 1B), our results demonstrate a steady and time-dependent increase in extracted lipids in adipocytes during terminal differentiation.

TSHR protein is expressed and localized on the cell surface of adipocytes

We next used indirect immunofluorescence to determine whether TSHR protein is detectable in day 20 EB-derived mature adipocytes. We stained these cells with goat anti-mouse
TSHR antibody followed by cy 3 affinipure-labeled donkey anti-goat IgG and observed them with fluorescent microscopy. As shown in Fig. 2, TSHR-positive cells were evident on the surface of the adipocytes that contained lipid droplets, but not in surrounding cells. No immunofluorescence was detected in a control experiment (Fig. 2). It should be noted that ES cellderived mature adipocytes contain one large lipid droplet.

\section{Adipogenic factors stimulate adipocyte differentiation and TSHR function}

Treatment with adipogenic factors during stage 4 EB differentiation caused a profound increase in adipocyte differentiation (Fig. 3). To investigate how adipogenic factors regulate the expression of TSHR and genes related to adipocyte differentiation, we compared mRNA levels of adipocyte differentiation markers in cells treated with adipogenic factors with those in untreated cells. Semi-quantitative RT-PCR analysis revealed an intense increase in $A L B P$ gene expression 

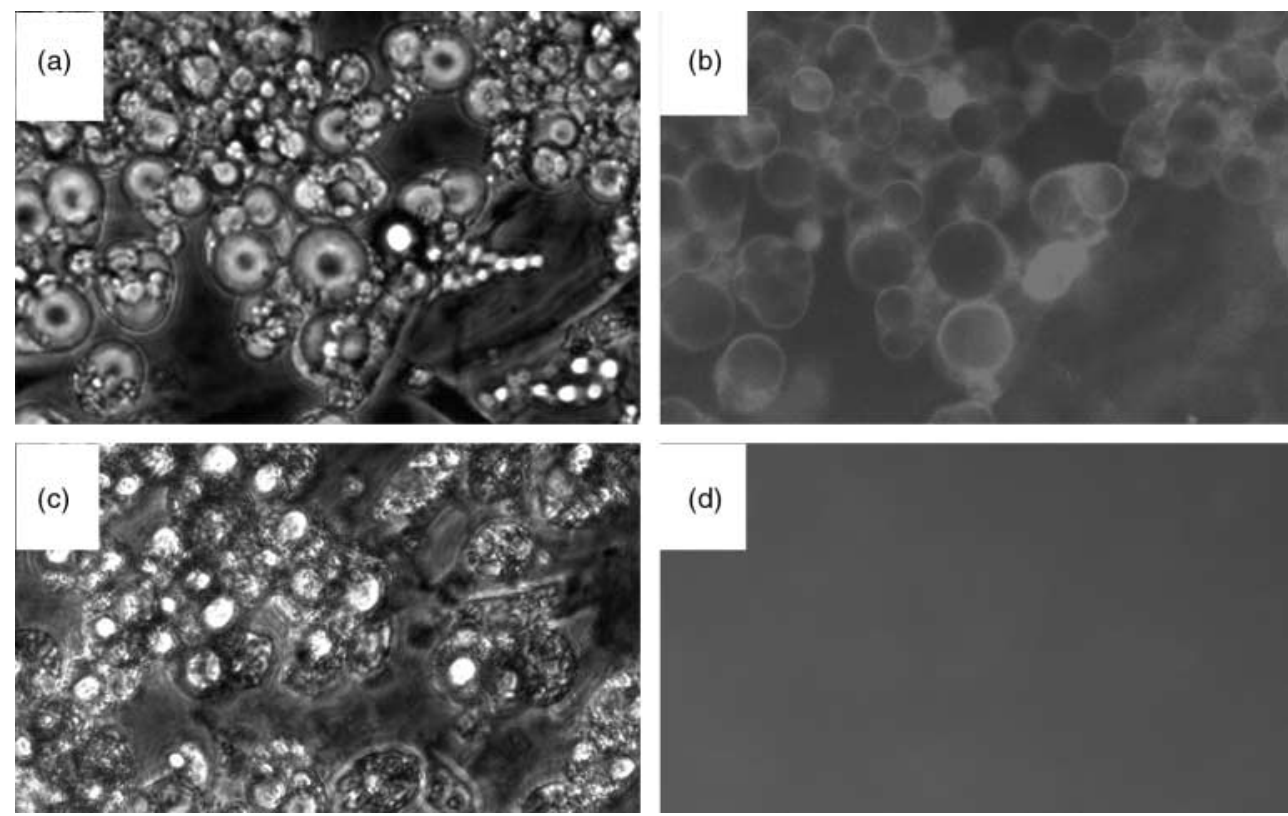

(d)

Figure 2 TSHR is expressed on the cell surface of differentiated adipocytes. The presence of TSHR after 20 days of differentiation was detected by immunofluorescent staining with an antibody to TSHR (red). Note that TSHR is in adipocytes that contained lipid droplets, but not in surrounding cells (b). Immunofluorescence was not detected when the experiment was done with an isotype control (d). Note that $a$ and $c$ are phase contrast images. Experiments were carried out thrice independently, and each time the same results were obtained. Representative photomicrographs are shown. Magnification, $\times 200$.

in cells treated with adipogenic factors (Fig. 4). Levels of TSHR gene expression in these cultures were also increased relative to control cultures (Fig. 4) but $C / E B P \alpha$ and $P P A R \gamma$ gene expression levels did not differ significantly between treated and untreated cultures (Fig. 4). Next, we assessed the functionality of TSHR in these adipocytes. EB-derived adipocytes from cultures treated with or without adipogenic factors were challenged with TSH and assayed for intracellular cAMP production using the Biotrack cAMP immunoassay system as described in Materials and Methods. Our results show that cells cultured in the terminal differentiation phase without adipogenic factors had a higher intracellular cAMP content when challenged with TSH than did the non-TSH-challenged group $\left(51 \cdot 1 \pm 2 \cdot 0\right.$ vs $24 \cdot 2 \pm 0 \cdot 7 \mathrm{fmol} / \mathrm{cell} \times 10^{-3}, P<0 \cdot 0005$; Fig. 5). Likewise, cells cultured with adipogenic factors during terminal differentiation achieved higher intracellular cAMP levels when challenged with TSH than did the non-TSHchallenged group $\left(84 \cdot 4 \pm 3 \cdot 4\right.$ vs $20 \cdot 2 \pm 2 \cdot 0 \mathrm{fmol} / \mathrm{cell} \times 10^{-3}$, $P<0 \cdot 0005)$. More importantly, the cells cultured with adipogenic factors showed nearly $1 \cdot 5$-fold higher intracellular cAMP content than cells cultured without adipogenic factors $(P<0 \cdot 005)$. This finding implies that adipogenic factors stimulate TSH-dependent cAMP production, perhaps due to more abundant TSHR expression in the adipocytes in these cultures. Our data also suggest that adenylyl cyclase is involved in the activation of TSH via the protein kinase A signaling pathway in mature adipocytes. Together, these results suggest that adipogenic factors play an important role in the conversion of ES cells to adipocytes. Furthermore, our data suggest that TSH signaling contributes to adipocyte differentiation via TSHR function.

\section{Effect of TSH treatment on adipocyte differentiation in the presence of adipogenic factors}

To investigate the role of TSH signaling in adipocyte differentiation, we added human recombinant TSH to ES cell cultures at various time points during stage 4 differentiation. After 20 days of differentiation, we measured lipid accumulation in these cultures and compared it with untreated cultures. Our results show that cultures treated with TSH at days 7, 10, 12, 16, and 18 of differentiation accumulated more lipids than did control cultures, indicating that TSH stimulates adipocyte differentiation at this stage (Fig. 6). We next assessed expression of $A L B P$, TSHR, and PPAR $\gamma$ genes to determine whether TSH-induced changes in lipid accumulation were reflected in the mRNA levels of adipogenic and TSHR genes. We found that although $A L B P$ and TSHR genes exhibited the greatest changes at day 12 (Fig. 6), no significant differences were observed for PPAR $\gamma$. These observations suggest that TSH is most able to stimulate adipocyte differentiation in the presence of adipogenic factors, and that TSH significantly increases the expression of TSHR and ALBP $(P<0 \cdot 05)$, but not PPAR $\gamma$ in 


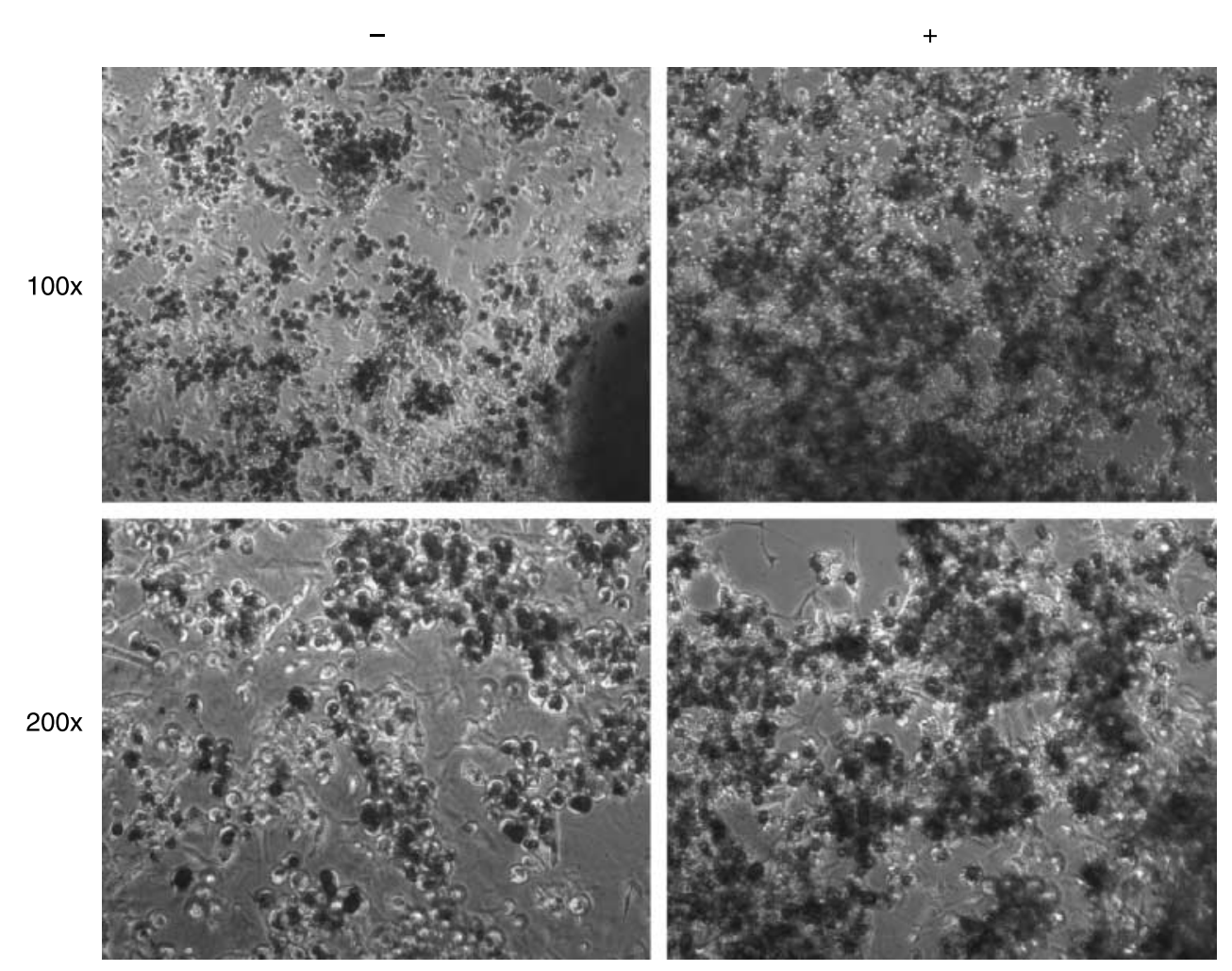

Figure 3 Effects of adipogenic factors on adipocyte differentiation. Examination of oil red O-stained adipocytes cultured for 15 days in adipocyte differentiation medium containing insulin, $T_{3}$, and rosiglitazone ( + ) by phase contrast microscopy. The cultures not treated with adipogenic factors $(-)$ are used as controls. Experiments were separately carried out at least thrice for each culture condition, and each time the same results were obtained.

these cultures after 12 days of differentiation. Therefore, TSH stimulates adipocyte differentiation, resulting in enhanced adipogenesis and increased $A L B P$ and TSHR gene expression.

Effect of TSH treatment on adipocyte differentiation in the absence of adipogenic factors

To investigate whether TSH can replace adipogenic factors in the conversion of ES cells into adipocytes, we added TSH to ES cell cultures at various time points during stage $4 \mathrm{~EB}$ differentiation in the absence of adipogenic factors (Fig. 7). We found a significant increase in the lipid accumulation assay when TSH was added at day $12(P<0 \cdot 05$; Fig. 7$)$. We also found that $A L B P$, TSHR, and PPAR $\gamma$ gene expression were enhanced when TSH was added at days 7, 10, and 12 of differentiation; however, these differences were not significant $(P>0 \cdot 05$; Fig. 7$)$. Together, this finding suggests that TSH signaling either directly or indirectly impacts major pathways for adipocyte differentiation.

\section{Discussion}

In vitro differentiation of ES cells is a valuable model to study the commitment and differentiation of embryonic adipose cells.
The technology to rapidly generate adipocytes has been described, but the use of in vitro differentiation of ES cells to analyze the physiological role of TSH and TSHR in this process is just beginning. In the present study, we use RT-PCR analysis, oil red $\mathrm{O}$ staining, lipid accumulation assays, immunofluorescent staining, and intracellular cAMP assays to document the expression and function of TSHR in adipocytes derived from ES cells. The current approach relies on a murine ES cell line and a four-stage differentiation strategy that enables the efficient production of adipocytes in a reproducible and developmentally regulated manner. Although TSHR has not been reported in ES cell-derived adipocytes, we have previously reported that murine ES cells can differentiate into thyrocyte-like cells in vitro and that the expression of TSHR may be important in this differentiation (Lin et al. 2003, Arufe et al. 2006, Lin \& Davies 2006). We now report that this ES cell-based system - in addition to producing cells in the thyroid lineage - can generate cells in the adipose lineage that express functional TSHR.

The experimental approach described here emphasizes the power of appropriate stimulatory factors in the generation of adipocytes from ES cells. We have shown that retinoic acid treatment followed by stimulation with insulin, $\mathrm{T}_{3}$, and rosiglitazone generates many EB outgrowths containing adipocytes with fat droplets. RT-PCR analysis of the differentiating EB cells revealed the temporal appearance of mRNA transcripts 


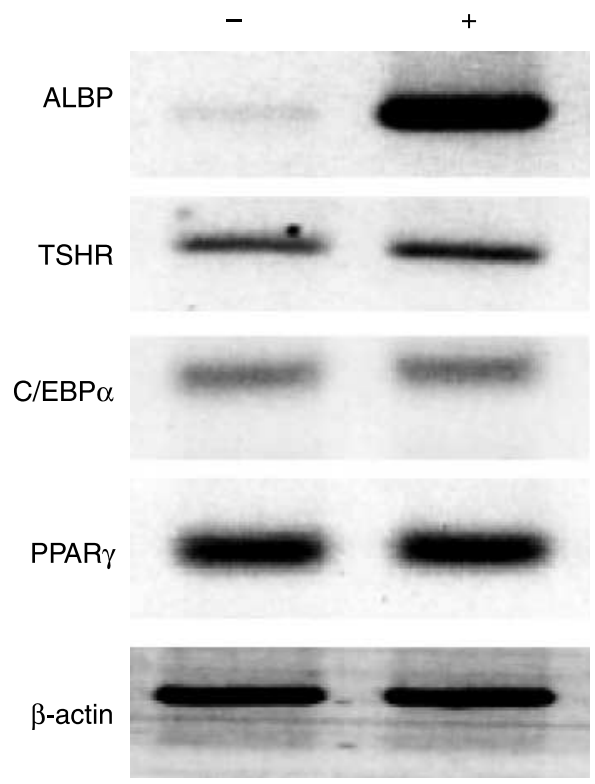

Figure 4 Adipogenic factors stimulate $A L B P$ and TSHR gene expression. After 20 days of differentiation, the expression of adipocyte markers $(A L B P, C / E B P \alpha$, and $P P A R \gamma)$ and $T S H R$ were analyzed by RT-PCR in cultures treated with adipogenic factors $(+)$. Untreated cultures $(-)$ serve as controls. Experiments were separately carried out at least thrice for each culture condition, and each time the same results were obtained.

for a number of adipocyte differentiation genes including $A L A P$, $C / E B P \alpha$, and $P P A R \gamma$. Importantly, we found that EB-derived preadipocyte differentiation is closely correlated with TSHR expression and function. This finding is consistent with previous studies of $3 \mathrm{~T}_{3}-\mathrm{L} 1$ preadipocytes and rat preadipocyte primary

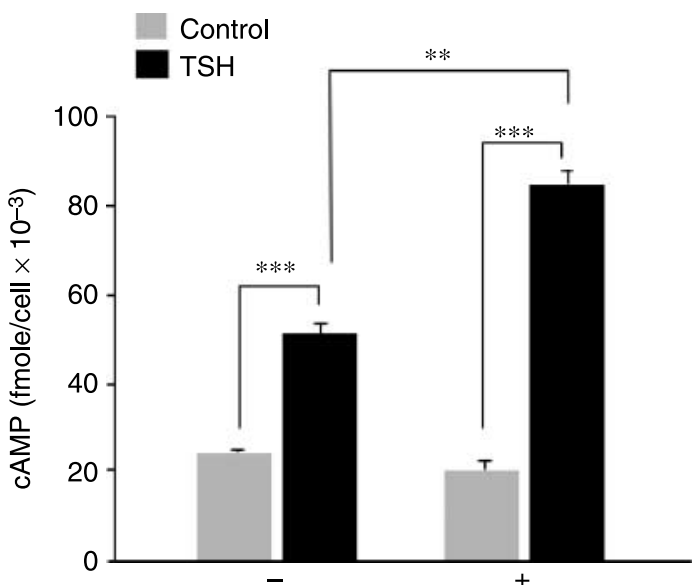

Figure 5 cAMP response in TSH-stimulated differentiated adipocytes. After 20 days of differentiation, intracellular cAMP levels were measured in cell lysates from cultures treated with adipogenic factors (+) using the Biotrak cAMP immunoassay system as described in Materials and Methods. Untreated cultures $(-)$ were used as controls. Data represent the mean \pm S.E.M. of three independent experiments, each performed in duplicate. $* * P<0 \cdot 005, * * * P<0 \cdot 0005$. cultures (Haraguchi et al. 1996a, Bell et al. 2002). Our immunofluorescent observations confirmed TSHR expression on the cell surface of mature, ES cell-derived adipocytes. Intracellular cAMP assays further revealed that this TSHR mediates a signal upon TSH stimulation. Our results indicate that TSH is important for late adipogenic differentiation. TSH treatment of differentiating ES cell-derived EBs increased adipogenesis either in the presence or absence of classic adipogenic factors. Together, these observations suggest a pro-adipogenic role for TSH in the conversion of ES cells into adipocytes.

TSH has been implicated in the induction of lipolysis (Vizek et al. 1979). It is known that TSH peaks within the first hours after birth at levels 50-100 times higher than that found in adults (Janson et al. 1998). In vitro studies have demonstrated that TSH can induce lipolysis in adipocytes from neonates, and that this lipolysis can be completely blocked by TSH antiserum and inhibitory TSHR antibodies (Marcus et al. 1988, Janson et al. 1998). The TSHR is a G-protein-coupled glycoprotein hormone receptor with a large extracellular domain fused to a seven-membrane-spanning segment (Nagayama et al. 1989). Since TSHR was first cloned in 1989, it has been believed to be responsible solely for the control of thyroid follicular cell growth and thyroid hormone synthesis (Nagayama et al. 1989, Laugwitz et al. 1996). However, it is becoming increasingly clear that expression of TSHR is not confined to the thyroid gland, but is widely expressed in a variety of tissues (Francis et al. 1991, Endo et al. 1993, Feliciello et al. 1993, Heufelder et al. 1993). TSHR protein expression has been reported in fibroblasts and adipose tissue from the retro-orbital space of Graves' patients, where it may play a role in thyroid-associated ophthalmopathy (Bahn et al. 1998a,b, Starkey et al. 2003, Bahn 2004). A series of reports demonstrated that the orbital preadipocyte fibroblast is the primary target cell for immune response in the orbits of patients with Graves' ophthalmopathy (GO; Valyasevi et al. 1999, 2002, Starkey et al. 2003, Bahn 2004, Kumar et al. 2004). Although orbital preadipocyte fibroblasts do not express the TSHR, a significant increase in functional TSHR expression is evident in differentiating cells and mature adipocytes derived from GO patients (Valyasevi et al. 1999, Starkey et al. 2003, Kumar et al. 2004). Given that the expanded adipose tissue volume is attributable to de novo adipogenesis, these facts imply a possible link between adipogenesis and induction of the TSHR expression in orbital preadipocyte fibroblasts in GO. Recently, Zhang et al. (2006) reported that TSHR activation induces morphologic changes and lipid content in orbital preadipocytes derived from GO patients. TSHR activation also increases intracellular cAMP accumulation in preadipocytes. Their model suggests that TSHR activation stimulates the early stages of adipogenesis but inhibits the terminal stages of differentiation on human orbital preadipocytes in vitro (Zhang et al. 2006).

TSHR expression has also been detected in brown and white adipose tissues in the guinea pig (Roselli-Rehfuss et al. 1992). Moreover, Bell et al. (2000) have detected the expression of TSHR mRNA and protein in human 
A

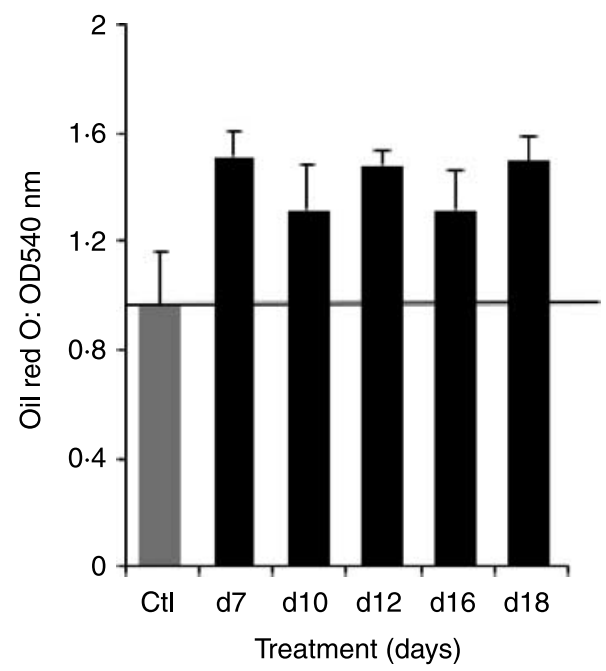

B

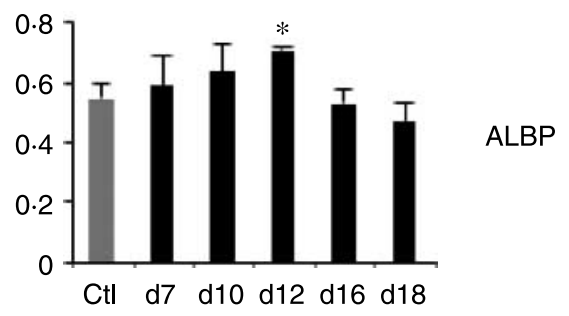

TSHR

PPAR $\gamma$

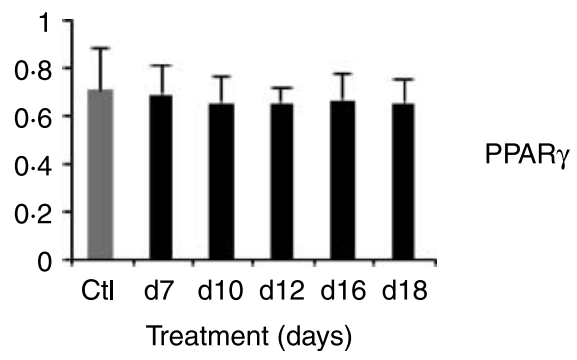

Figure 6 Effect of TSH treatment on adipocyte differentiation in the presence of adipogenic factors. Cells in duplicate wells were exposed to $1 \mathrm{mU} / \mathrm{ml}$ human recombinant TSH in the presence of adipogenic factors at indicated time points and harvested after 20 total days of differentiation. (A) Stained lipids were extracted with isopropyl alcohol and the absorbance at $540 \mathrm{~nm}$ was measured. Data are expressed as mean \pm s.E.M. The values shown are the average from three separate experiments each done in duplicate. ${ }^{*} P<0 \cdot 05$. (B) RT-PCR was performed to detect the expression of ALBP, TSHR, and PPAR genes. Numbers on the bottom of each figure indicate the day on which TSH was added. Relative gene expression was determined by normalization to that of $\beta$-actin control ( $Y$-axis). Each experiment was performed with its own control, so to normalize between experiments, the fold increases were divided by the fold increase for each specific control. Error bars represent the standard deviation of triplicate experiments. ${ }^{*} P<0 \cdot 05$.

preadipocytes from abdominal subcutaneous and omental tissues. Despite these observations, the specific role of TSHR in adipose biology remains to be elucidated. Haraguchi $e t$ al. (1996a) previously reported that preadipocyte differentiation in rats is accompanied by TSHR expression. Although cultured rat preadipocytes are a good model system for studying the physiological role of TSHR in adipose tissues, they have limitations. In particular, because rat preadipocytes are prepared directly from epididymal, perirenal, and subcutaneous fat from the inguinal regions of male SD rats (Haraguchi et al. 1996a), they are often contaminated with other cell types and can be difficult to maintain. In addition, both rat preadipocytes and the murine $3 \mathrm{~T}_{3}-\mathrm{L} 1$ preadipocyte cell line, a well-established model of adipogenesis, consist of already committed adipose progenitor cells and permit study of terminal differentiation only (Bell et al. 2002). To better understand the mechanisms that control adipocyte differentiation, it is essential to generate an enriched population of proliferating adipose progenitor cells and identify genes and factors specifically involved in regulating adipocyte activity. In vitro differentiation of ES cells toward the adipogenic lineage could provide an alternative source of adipocytes for study and offers the possibility to study the regulation of the first steps of adipogenesis. This ES cell differentiation approach has significantly impacted on the field of basic research, in which the contributions of key molecules and signaling pathways to the adipogenic differentiation program can be investigated. Furthermore, the ability to genetically engineer stem cell may allow clinicians to test the effects of current drugs and to develop clinically relevant screening assays that would not otherwise be possible. ES cell differentiation model represents an important model system to study the development of adipocytes. The expression of TSHR during early preadipocyte differentiation in our ES 
A

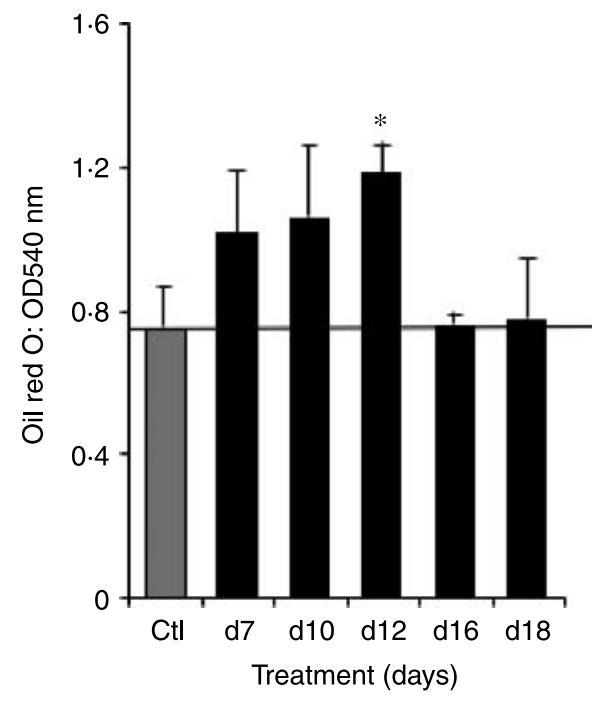

B

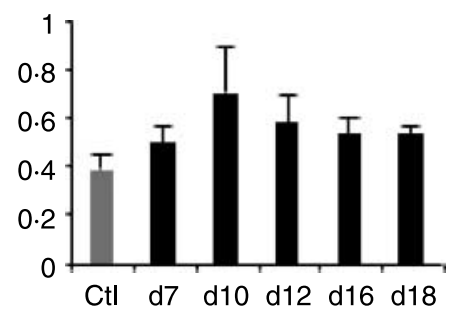

TSHR

PPAR $\gamma$

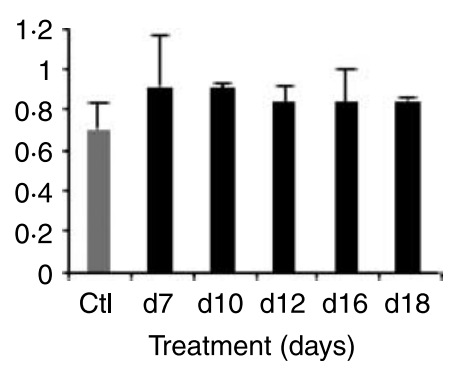

Figure 7 Effect of TSH treatment on adipocyte differentiation in the absence of adipogenic factors. Cells in duplicate wells were exposed to $1 \mathrm{mU} / \mathrm{ml}$ human recombinant TSH in the absence of adipogenic factors at indicated time points and harvested after 20 total days of differentiation. (A) Lipid accumulation by extraction of stained lipid with isopropyl alcohol and the absorbance at $540 \mathrm{~nm}$ was measured. Data are expressed as mean \pm S.E.M. The values shown are the average from three separate experiments each done in duplicate. $* P<0 \cdot 05$. (B) RT-PCR was performed to detect the expression of $A L B P, T S H R$, and PPAR genes. Numbers on the bottom of each figure indicate the day on which TSH was added. $Y$-axis indicates relative gene expression normalized with $\beta$-actin control. Each experiment was performed with its own control, so to normalize between experiments, the fold increases were divided by the fold increase for each specific control. Error bars represent the standard deviation of triplicate experiments. ${ }^{*} P<0 \cdot 05$.

cell-based differentiation could provide an ideal cellular model system to delineate the role of TSHR in adipose development.

Our results indicate that TSH can induce differentiation of murine ES cells to adipocytes in the absence of adipogenic factors at a high level. The in vitro concentration of TSH in our study is lower than what was reported in literature in mice ( $60 \mathrm{mU} / \mathrm{ml}$; Abe et al. 2003). However, this concentration is much higher than those in humans $(0 \cdot 4-4 \cdot 2 \mathrm{mU} / \mathrm{dl})$. Although we suggest that this observation may be physiologically relevant, clearly, more studies are needed to elucidate these probabilities as well as to clarify the precise maturation stage of ES cell-derived adipocytes under the effect of TSH. Furthermore, we found that adipocyte differentiation along with $A L B P$ and TSHR gene expression were greatly enhanced when cultures were treated with TSH at day 12 . This finding indicates that TSH stimulates adipocyte differentiation and TSHR expression. As reported in literature, TSH in human fetal thyroid cells positively regulated the TSHR in vitro (Huber \& Davies 1990). We have previously reported that TSH was necessary to maintain the expression of the TSHR gene during EB differentiation into thyrocytes in culture (Lin et al. 2003). It is conceivable that a positive feedback cycle is present between TSH and TSHR in this ES cell differentiation model.

In order to further characterize the role of TSHR in adipocyte differentiation, we studied TSH signaling in ES cell-derived adipocytes. Bell et al. (2002) reported that TSH acts as a survival factor in $3 \mathrm{~T}_{3}-\mathrm{L} 1$ preadipocytes; although it does not stimulate cAMP accumulation in these cells, TSH activates a PI3K-PKB/Akt-p70 S6 Kinase (S6K) signaling pathway. With respect to the present study, although it is clear that TSH stimulates cAMP accumulation in differentiated adipocytes, it is not clear whether TSH modulates 
preadipocyte survival and whether TSH signaling leads to p70 S6K activation. Further characterization of these ES cell-derived preadipocytes and adipocytes might help us understand the TSH signaling pathway and the mechanisms by which TSH regulates adipogenesis in these cells.

In summary, the present work demonstrates that TSHR is expressed in a time- and adipogenic-dependent manner in differentiating ES cells. Generation of adipocytes from ES cells can be achieved in 20 days using culture conditions previously established for the growth and differentiation of murine ES cells. Based on our studies, this murine ES cell-based system may be an ideal way to optimize adipocyte production and analyze TSH's function in adipose development. In addition, this murine ES cell-based system may allow the dissection of the fine controls of lipolysis, a complex metabolic process occurring during times of stress or nutrient deprivation.

\section{Acknowledgements}

We wish to thank Dr Gordon Keller and members of his laboratory for all their support and encouragement through all phases of this project. This work was supported by grant R01DK068057 from the National Institutes of Health to $\mathrm{R}-\mathrm{Y} \mathrm{L}$. The authors declare that there is no conflict of interest that would prejudice the impartiality of this scientific work.

\section{References}

Abe E, Marians RC, Yu W, Wu XB, Ando T, Li Y, Iqbal J, Eldeiry L, Rajendren G, Blair HC et al. 2003 TSH is a negative regulator of skeletal remodeling. Cell 115 151-162.

Arufe MC, Lu M, Kubo A, Keller G, Davies TF \& Lin RY 2006 Directed differentiation of mouse embryonic stem cells into thyroid follicular cells. Endocrinology 147 3007-3015.

Bahn RS 2004 TSH receptor expression in orbital tissue and its role in the pathogenesis of Graves' ophthalmopathy. Journal of Endocrinological Investigation 27 216-220.

Bahn RS, Dutton CM, Joba W \& Heufelder AE 1998a Thyrotropin receptor expression in cultured Graves' orbital preadipocyte fibroblasts is stimulated by thyrotropin. Thyroid 8 193-196.

Bahn RS, Dutton CM, Natt N, Joba W, Spitzweg C \& Heufelder AE 19986 Thyrotropin receptor expression in Graves' orbital adipose/connective tissues: potential autoantigen in Graves' ophthalmopathy. Journal of Clinical Endocrinology and Metabolism 83 998-1002.

Bain G, Kitchens D, Yao M, Huettner JE \& Gottlieb DI 1995 Embryonic stem cells express neuronal properties in vitro. Developmental Biology 168 342-357.

Baron DN 1956 Hypothyroidism; its aetiology and relation to hypometabolism, hypercholesterolaemia, and increase in body-weight. Lancet 271 277-281.

Baxa CA, Sha RS, Buelt MK, Smith AJ, Matarese V, Chinander LL, Boundy KL \& Bernlohr DA 1989 Human adipocyte lipid-binding protein: purification of the protein and cloning of its complementary DNA. Biochemistry 28 8683-8690.

Bell A, Gagnon A, Grunder L, Parikh SJ, Smith TJ \& Sorisky A 2000 Functional TSH receptor in human abdominal preadipocytes and orbital fibroblasts. American Journal of Physiology and Cell Physiology 279 C335C340.

Bell A, Gagnon A, Dods P, Papineau D, Tiberi M \& Sorisky A 2002 TSH signaling and cell survival in 3T3-L1 preadipocytes. American Journal of Physiology and Cell Physiology 283 C1056-C1064.
Choi K, Kennedy M, Kazarov A, Papadimitriou JC \& Keller G 1998 A common precursor for hematopoietic and endothelial cells. Development $125725-732$.

Crisp MS, Lane C, Halliwell M, Wynford-Thomas D \& Ludgate M 1997 Thyrotropin receptor transcripts in human adipose tissue. Journal of Clinical Endocrinology and Metabolism 82 2003-2005.

Danese MD, Ladenson PW, Meinert CL \& Powe NR 2000 Clinical review 115: effect of thyroxine therapy on serum lipoproteins in patients with mild thyroid failure: a quantitative review of the literature. Journal of Clinical Endocrinology and Metabolism 85 2993-3001.

Davies TF, Teng CS, McLachlan SM, Smith BR \& Hall R 1978 Thyrotropin receptors in adipose tissue, retro-orbital tissue and lymphocytes. Molecular and Cellular Endocrinology 9 303-310.

Endo T, Ohno M, Kotani S, Gunji K \& Onaya T 1993 Thyrotropin receptor in non-thyroid tissues. Biochemical and Biophysical Research Communications $190774-779$.

Evans MJ \& Kaufman MH 1981 Establishment in culture of pluripotential cells from mouse embryos. Nature 292 154-156.

Feliciello A, Porcellini A, Ciullo I, Bonavolonta G, Avvedimento EV \& Fenzi G 1993 Expression of thyrotropin-receptor mRNA in healthy and Graves' disease retro-orbital tissue. Lancet 342 337-338.

Field SJ, Johnson RS, Mortensen RM, Papaioannou VE, Spiegelman BM \& Greenberg ME 1992 Growth and differentiation of embryonic stem cells that lack an intact c-fos gene. PNAS 89 9306-9310.

Francis T, Burch HB, Cai WY, Lukes Y, Peele M, Carr FE, Wartofsky L \& Burman KD 1991 Lymphocytes express thyrotropin receptor-specific mRNA as detected by the PCR technique. Thyroid $1223-228$.

Gorman RR, Hamberg M \& Samuelsson B 1975 Inhibition of basal and hormone-stimulated adenylate cyclase in adipocyte ghosts by the prostaglandin endoperoxide prostaglandin H2. Journal of Biological Chemistry 250 6460-6463.

Hak AE, Pols HA, Visser TJ, Drexhage HA, Hofman A \& Witteman JC 2000 Subclinical hypothyroidism is an independent risk factor for atherosclerosis and myocardial infarction in elderly women: the Rotterdam Study. Annals of Internal Medicine 132 270-278.

Haraguchi K, Shimura H, Lin L, Endo T \& Onaya T 1996a Differentiation of rat preadipocytes is accompanied by expression of thyrotropin receptors. Endocrinology 137 3200-3205.

Haraguchi K, Shimura H, Lin L, Saito T, Endo T \& Onaya T 1996 b Functional expression of thyrotropin receptor in differentiated 3T3-L1 cells: a possible model cell line of extrathyroidal expression of thyrotropin receptor. Biochemical and Biophysical Research Communications 223 193-198.

Haraguchi K, Shimura H, Kawaguchi A, Ikeda M, Endo T \& Onaya T 1999 Effects of thyrotropin on the proliferation and differentiation of cultured rat preadipocytes. Thyroid 9 613-619.

Heufelder AE, Dutton CM, Sarkar G, Donovan KA \& Bahn RS 1993 Detection of TSH receptor RNA in cultured fibroblasts from patients with Graves' ophthalmopathy and pretibial dermopathy. Thyroid 3 297-300.

Hoogwerf BJ \& Nuttall FQ 1984 Long-term weight regulation in treated hyperthyroid and hypothyroid subjects. American Journal of Medicine $\mathbf{7 6}$ 963-970.

Huber GK \& Davies TF 1990 Human fetal thyroid cell growth in vitro: system characterization and cytokine inhibition. Endocrinology 126 869-875.

Iacobellis G, Ribaudo MC, Zappaterreno A, Iannucci CV \& Leonetti F 2005 Relationship of thyroid function with body mass index, leptin, insulin sensitivity and adiponectin in euthyroid obese women. Clinical Endocrinology 62 487-491.

Imaizumi M, Akahoshi M, Ichimaru S, Nakashima E, Hida A, Soda M, Usa T, Ashizawa K, Yokoyama N, Maeda R et al. 2004 Risk for ischemic heart disease and all-cause mortality in subclinical hypothyroidism. Journal of Clinical Endocrinology and Metabolism 89 3365-3370.

Janson A, Rawet H, Perbeck L \& Marcus C 1998 Presence of thyrotropin receptor in infant adipocytes. Pediatric Research 43 555-558.

Kawasaki H, Mizuseki K, Nishikawa S, Kaneko S, Kuwana Y, Nakanishi S, Nishikawa SI \& Sasai Y 2000 Induction of midbrain dopaminergic neurons from ES cells by stromal cell-derived inducing activity. Neuron 28 31-40. 
Kehat I, Khimovich L, Caspi O, Gepstein A, Shofti R, Arbel G, Huber I, Satin J, Itskovitz-Eldor J \& Gepstein L 2004 Electromechanical integration of cardiomyocytes derived from human embryonic stem cells. Nature Biotechnology 22 1282-1289.

Keller GM 1995 In vitro differentiation of embryonic stem cells. Current Opinion in Cell Biology 7 862-869.

Keller G, Kennedy M, Papayannopoulou T \& Wiles MV 1993 Hematopoietic commitment during embryonic stem cell differentiation in culture. Molecular and Cellular Biology 13 473-486.

Konishi J, Iida Y, Kasagi K, Ikekubo K, Kuma K \& Torizuka K 1982 Adipocyte-TSH-receptor-related antibodies in Graves' disease detected by immunoprecipitation. Endocrinologia Japonica 29 219-226.

Kumar S, Coenen MJ, Scherer PE \& Bahn RS 2004 Evidence for enhanced adipogenesis in the orbits of patients with Graves' ophthalmopathy. Journal of Clinical Endocrinology and Metabolism 89 930-935.

Laugwitz KL, Allgeier A, Offermanns S, Spicher K, Van Sande J, Dumont JE \& Schultz G 1996 The human thyrotropin receptor: a heptahelical receptor capable of stimulating members of all four G protein families. PNAS $\mathbf{9 3}$ $116-120$.

Lin RY \& Davies TF 2006 Derivation and characterization of thyrocyte-like cells from embryonic stem cells in vitro. Methods in Molecular Biology 330 249-261.

Lin RY, Kubo A, Keller GM \& Davies TF 2003 Committing embryonic stem cells to differentiate into thyrocyte-like cells in vitro. Endocrinology 144 2644-2649.

Lumelsky N, Blondel O, Laeng P, Velasco I, Ravin R \& McKay R 2001 Differentiation of embryonic stem cells to insulin-secreting structures similar to pancreatic islets. Science 292 1389-1394.

Marcus C, Ehren H, Bolme P \& Arner P 1988 Regulation of lipolysis during the neonatal period. Importance of thyrotropin. Journal of Clinical Investigation 82 1793-1797.

Martin GR 1981 Isolation of a pluripotent cell line from early mouse embryos cultured in medium conditioned by teratocarcinoma stem cells. PNAS $\mathbf{7 8}$ 7634-7638.

Matarese V \& Bernlohr DA 1988 Purification of murine adipocyte lipidbinding protein. Characterization as a fatty acid- and retinoic acid-binding protein. Journal of Biological Chemistry 263 14544-14551.

Moulin de Moraes CM, Mancini MC, de Melo ME, Figueiredo DA, Villares SM, Rascovski A, Zilberstein B \& Halpern A 2005 Prevalence of subclinical hypothyroidism in a morbidly obese population and improvement after weight loss induced by Roux-en-Y gastric bypass. Obesity Surgery 15 1287-1291

Mullin BR, Lee G, Ledley FD, Winland RJ \& Kohn LD 1976 Thyrotropin interactions with human fat cell membrane preparations and the finding of soluble thyrotropin binding component. Biochemical and Biophysical Research Communications 69 55-62.
Nagayama Y, Kaufman KD, Seto P \& Rapoport B 1989 Molecular cloning, sequence and functional expression of the cDNA for the human thyrotropin receptor. Biochemical and Biophysical Research Communications $1651184-1190$.

Phillips BW, Vernochet C \& Dani C 2003 Differentiation of embryonic stem cells for pharmacological studies on adipose cells. Pharmacological Research 47 263-268.

Roselli-Rehfuss L, Robbins LS \& Cone RD 1992 Thyrotropin receptor messenger ribonucleic acid is expressed in most brown and white adipose tissues in the guinea pig. Endocrinology 130 1857-1861.

Starkey KJ, Janezic A, Jones G, Jordan N, Baker G \& Ludgate M 2003 Adipose thyrotrophin receptor expression is elevated in Graves' and thyroid eye diseases ex vivo and indicates adipogenesis in progress in vivo. Journal of Molecular Endocrinology 30 369-380.

Trokoudes KM, Sugenoya A, Hazani E, Row VV \& Volpe R 1979 Thyroid-stimulating hormone (TSH) binding to extrathyroidal human tissues: TSH binding to extrathyroidal human tissues: TSH and thyroid-stimulating immunoglobulin effects on adenosine $3^{\prime}, 5^{\prime}$-monophosphate in testicular and adrenal tissues. Journal of Clinical Endocrinology and Metabolism 48 919-923.

Valyasevi RW, Erickson DZ, Harteneck DA, Dutton CM, Heufelder AE, Jyonouchi SC \& Bahn RS 1999 Differentiation of human orbital preadipocyte fibroblasts induces expression of functional thyrotropin receptor. Journal of Clinical Endocrinology and Metabolism $842557-2562$.

Valyasevi RW, Harteneck DA, Dutton CM \& Bahn RS 2002 Stimulation of adipogenesis, peroxisome proliferator-activated receptor-gamma ( $\operatorname{PPAR} \gamma$ ), and thyrotropin receptor by PPAR $\gamma$ agonist in human orbital preadipocyte fibroblasts. Journal of Clinical Endocrinology and Metabolism 87 2352-2358.

Visscher TL \& Seidell JC 2001 The public health impact of obesity. Annual Review of Public Health 22 355-375.

Vizek K, Razova M \& Melichar V 1979 Lipolytic effect of TSH, glucagon and hydrocortisone on the adipose tissue of newborns and adults in vitro. Physiologia Bohemoslovaca 28 325-331.

Zhang L, Baker G, Janus D, Paddon CA, Fuhrer D \& Ludgate M 2006 Biological effects of thyrotropin receptor activation on human orbital preadipocytes. Investigative Ophthalmology and Visual Science 47 $5197-5203$.

\section{Received in final form 10 October 2007 Accepted 19 October 2007 Made available online as an Accepted Preprint 19 October 2007}

